Session 2248

\title{
The Medical Theory of Engineering and Technology Education
}

\author{
Hamid Khan \\ Purdue University \\ West Lafayette, IN 47907 \\ ahkhan@tech.purdue.edu
}

"Problem solving in general, whether it is used to solve mathematical problems at the school level, or in serious research that may lead to major (medical) breakthroughs, or simply to solve problems we encounter during our daily lives, is an indispensable skill that every well-educated person should acquire. There are some gifted people who have attained these skills in a natural way. Yet the vast majority of us require(s) some training to develop proper problem solving skills. Providing this training is perhaps one of the most important responsibilities resting with our educators. All too often students 'pick up' problem solving skills through experience or as a bye product of doing exercises in mathematics or science classes. Watching the teacher or the textbook author plow through some problem situations can also lead to some lasting spin-offs." Herbert A. Hauptman, Nobel Laureate in Chemistry.

The reason Hauptman has been quoted for this paper is obvious. A medical theory of effective engineering and technology and problem solving will be discussed. The other objective of this paper is the development of a concept of problem solving in Industrial Technology majors from theory to practice. In studying Industrial Technology subjects, where the rigor is not on mathematics or deep concepts, but problem solution, students are exposed to some classical techniques of Industrial Engineering, Production and Operations Research, and Engineering Economics problems. Although some good students "all too often 'pick up' problem solving skills through experience or as a bye product of doing exercises," it has been invariably seen that they never learn the problem solving strategies for efficient and elegant solutions.

This paper will discuss some of the problem solving strategies for teaching effectiveness in an industrial technology classroom setting, where the higher level engineering concepts must be translated to efficient and elegant solutions for applications. The students' learning effectiveness will be characterized by firm evidence, that they learned a theory for the sake of practice.

\section{Introduction}

This paper examines, in regard to similarities and differences, the constructs and philosophical approaches of the three paradigms of inquiry and problem solving in engineering technology (ET) education: (1) Positivistic, (2) Interpretive, and (3) Critical. It also tries to look into the major frameworks of constantly changing relationship between theory and practice. Critically examining these frameworks, an effort was made to see if any one of the frameworks has contributed most to the body of knowledge in ET education, and which one holds the most promise for the future. 


\section{'Theory and practice of problem solving' and Other Major Frameworks}

Cervero (1991), speaking about the medical model of education, offers four critical frameworks of theory and practice and eventually develops the medical model: 'education without theory', 'theory as a foundation for practice', 'theory in practice' and 'theory and practice for emancipation'. This last and most useful theory further suggests that it is a prescription for the 'student' who accepts that the prescription will be 'obeyed' and is most applicable to workplace learning. It, in fact, provides reformation in the work place when taken as tool and agent for reform and brings about needed emancipation. This 'emancipation model' has been the building block of the most radical model, the medical model of emancipatory education. [1]

In education without theory he argues that there is no consideration of a body of knowledge. This tradition still persists as some educators work without this body of knowledge. Surprisingly enough, these people are also sometimes successful practitioners who have no theory to support their practices. This has compelled [4] Houle $(1964,1980)$ to ponder, "Can the great lore of the creative but untrained pioneers of education be studied so that it can be passed on in a more systematic fashion?" (p.82)

The concept of theory as the foundation for practice suggests that theory should be applied to practice of teaching and learning. This theory is the body of knowledge that has been generated by a procedural scientific research. Thus, scientific knowledge is the basis of practice. Aldus Huxley has said that pursuit of theoretical knowledge may lead us to practice, but practicing without theory may not reverse generate a relevant theory. Similarly Darkenwald and Merriam (1982) profess, "Theory without practice leads to empty idealism, and action without philosophical reflection is mindless activism". [2]

Theory in practice is a view slightly different from the others in regard to the relationship of theory to practice. Practice comes from tacit knowledge that guides a person's work. Theory can be derived from practice. This needs the self reflections of practitioners, which Carr (1980) believes, help in "...closing the gap between theory and practice." Schon $(1983,1987)$ believes that a reflective practitioner is one who uses repertoires of practical knowledge to understand and form a coherent problem that can be solved (Cervero, 1991, p.27). [1]

The concept of theory and practice for emancipation (medical theory) is a viewpoint, which is deep rooted in transformational theory of learning. This viewpoint asserts that theory and practice are indivisible and the focus lies on the relationship of theory and practice.

Cervero's treatment of the above four frameworks sheds light on his own belief that the eventual relationship between theory and practice is a negotiated settlement that must be arrived at by real people (teacher and student) in real situations, where context plays an important role. Schon however believes that in practice, this requires educators and critical action-researchers are committed to providing reformation in the immediate learning communities to "progressively incorporate students into their collaborative enterprise of self-reflection"

[1] Finally, Cervero (1991) puts it so succinctly for "continuing educators can become more 
effective by improving their ability to make better judgments. Where the dominant view assumes well defined problems, the new approach assumes that professionals construct the problem from the situation; that is the professionals construct their practice in the swamp of the real world, where the problems do not present themselves as well-formed, unambiguous structures but rather as messy indeterminate situations. Because professionals make judgments about the problems to be solved, this approach stresses the need to be critically aware of these judgments and their implications." (Cervero, 1991, p.109).

\section{Positivist, Interpretive and Critical Frameworks}

The Positivistic view of theory and practice asserts that scientific explanations can be given to educational decisions and outcomes. Challenging the above precept of the positivist ideology. [3] Carr and Kemmis (1986) contend that educational decisions are not neatly packaged into instrumental questions of means and ends, and thus, cannot be made absolutely clear cut. They say, if theory and practice are simply divided between facts and values, education will be value-laden to defeat the whole purpose of objectivity.

A position that agrees with Cervero, supported by Carr and Kemmis (1986), is that positivists, ET professionals engage in educational situations in the same way as scientists study natural phenomena according to a set of some governing law. " But by so treating these basic features as 'natural entities', this kind of research will always be biased toward prevailing educational arrangements and its theories will be structured in favor of 'status quo'" (Carr and Kemmis, 1986. p. 78). [3]

The interpretive approach to theory and practice of education is the identification of the meaning of real actions in real situations. Thus, practice is attached to theory via an individual's selfreflection. By this definition, the theory-practice relationship is two-way, mutually affecting each other and correcting each other. Carr and Kemmis [3] critically examine the interpretive view:

If there is any truth in the claim that the interpretive approach fails to explain the relationship between people's expectation of reality and the social conditions in which these interpretations occur, then it also offers an inadequate account of how theory relates to practice. For interpretive theories claim that by clarifying the meanings that individuals give to their actions, they overcome problems of communication between different social groups and thereby help people to change the way they think about what they or other social groups are doing. (Carr and Kemmis, 1986)

The interpretive view may thus be challenged by positivistic scholars and may demonstrate difference in approach, but it is also similar in demanding from the scholar a detached view of objectivity.

The critical approach to the understanding of theory to practice lies in the inseparability of theory and practice. This has been debated from the days of Aristotle to the days of Habermas's culminating in the theory of critical social science. The critical social science extracts meanings and interpretations of practitioners and must meet the criteria of authenticity and self-reflection. (Carr and 
Kemmis (1986).[3]

The three schools of thought have very strong perceptions of their own paradigms as serving the best in the field of ET education.

\section{Body of Knowledge in Problem Solving}

All the three frameworks have contributed to education in their own perceived way, using their methodology and process. However, the critical theory (medical theory) tries to deal with the theory to practice (praxis) question honestly.

The interpretive approach tends to be more general, more easily understood by practitioners as it tries to emphasize the notion of concrete problems being solved by real people in real situations, as Cervero likes to say. However, as the initial thrust of education was in the positivistic approach, most of the body of knowledge generated was due to application of positivistic research in trying to validate educational objectives.

\section{Most Promising Framework}

The interpretive framework is the most promising one. Carr and Kemmis [3] have given a good treatise to the subject. The theory is based on tacit knowledge and values that guide individual's work. They state in support of this premise:

Practical deliberation has its roots in the disposition of the actor to act truly, rightly, wisely and prudently -- the disposition called 'phronesis' by Aristotle. It expresses itself in praxis -- informed action. ... Interpretive social science, historically, aims to serve such readers. It aims to educate: to deepen insight and to enliven commitment. Its work is the transformation of the consciousness, the differentiation of modes of awareness and the enlightenment of action. (Carr and Kemmis, 1986, p.93)

Authors like Argyris and Schon have extensively demonstrated the link of theory and practice for increasing professional effectiveness. Cervero has also written extensively on teaching effectiveness and continuing professional development of ET professionals engaged in teaching.

The interpretive framework, however, seems to be the most promising one, according to Carter (1983). For functioning in professional practice, [5] Carter (1983) says that the effective teacher/practitioner must be an astute student of his/her work environment, which testifies to the theory practice two-way street. He also contends that academic preparation of practitioners should help the students in professional practice, which is theory embedded in practice. He also promises that systematic inquiry is the hallmark of successful practice, which testifies that medical theory or model

of learning and practice are inseparable. Carr and Kemmis also agree with these important observations about educational and research practices.

In these times ... in education, the need for the profession to organize itself to support and protect its professional work is obvious. Moreover, if the central aim of education is the critical transmission, interpretation and development of the cultural 
traditions of our society, the need for a form of research which focuses its energies and resources on the policies, processes and practices by which this aim is pursued is obvious as well. Emancipatry action research, as a form of critical educational science, provides a means by which the teaching profession and educational research can be reformulated so as to meet these ends. Car and Kemmis (1986) pp. 224. [3]

In conclusion, the theory-practice debate will continue to go on. Preference of the most applicable paradigm, as we step into the millennium, will depend on praxis, which may take a balance between the two ends, or a 'middle of the road situation'.

\section{Reference}

[1] Cervero, R. (1991). Changing relationships between theory and practice. Adult education: Evolution and achievements in a developing field of study (pp. 19-41) San Francisco: Jossey Bass.

[2] Carr, W., and Kemmis, S. (1986). Becoming critical: Education, Knowledge and Action Research. London: Falmer. (chapters. 2,3,\& 5)

[3] Darkenwald G. and Merriam S. (1982) Field Research and Grounded Theory" in Changing Approaches to Studying of Adult Education, San Fracisco, Jossey Bass

[4] Houle, C.O. Continuing learning in the professions. San Francisco, Jossey Bass.

[5] Carter, G. (1983). A perspective on preparing adult educators. In S.M. Grabowski (Ed) Strengthening connection between education and performance, New directions for continuing education (pp.73-82), Jossey-Bass.

\section{HAMID KHAN}

Hamid Khan is an Assistant Professor with the School of Technology, Purdue University. He received his BS Degree in Mechanical Engineering from Utkal University, MS Degree in Industrial Engineering from University of Nebraska-Lincoln, MBA Degree in Operations Management from University of Texas at San Antonio, and a Doctor of Education Degree from Ball State University. Hamid is a registered Professional Engineer. He has been active in ASEE since 1991. His research and teaching interests are in Learning Models in Engineering and Technology, Teaching Effectiveness, and Continuous Professional Development of Engineering, Management and Technical Personnel. 